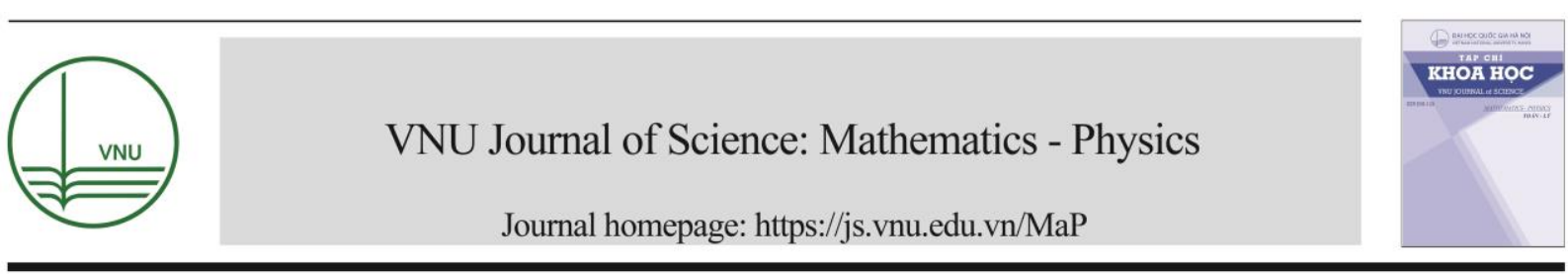

\title{
Study of Heating Rate Effect on Thermoluminescence Glow Curves of LiF: $\mathrm{Mg}, \mathrm{Cu}, \mathrm{P}$
}

\author{
Bui Thi Hong ${ }^{1, *}$, Vu Anh Hung ${ }^{1,3}$, Nguyen Quang Mien², Bui Van Loat ${ }^{1}$ \\ ${ }^{I}$ VNU University of Science, 334 Nguyen Trai, Thanh Xuan, Hanoi, Vietnam \\ ${ }^{2}$ Institute of Archaeology, 61 Phan Chu Trinh, Hanoi, Vietnam \\ ${ }^{3}$ Military Technical Academy, 236 Hoang Quoc Viet, Hanoi, Vietnam
}

Received 23 August 2017

Revised 19 October 2017; Accepted 08 January 2018

\begin{abstract}
Abtract: The samples of $\mathrm{LiF}: \mathrm{Mg}, \mathrm{Cu}, \mathrm{P}$ powder (xeri: GR-200) were irradiated by the gamma radiation resource with varied exposed dose. The glow curves of thermoluminescence (TL) material were observed with the defferent heating rates. The influence of heating rate on the thermoluminescence property of $\mathrm{LiF}: \mathrm{Mg}, \mathrm{Cu}, \mathrm{P}$ was analyzed. The results showed that as the heating rate increases, the peak intensity at the maximum decreases and shifts to higher temperature. The thermoluminesecnce sensitivity of the material also changes and has the optimal value at $6^{\circ} \mathrm{C} / \mathrm{s}$. This value is also adaptable for measurement of natural environmental and archaeologicaldose.
\end{abstract}

Keywords: Thermoluminescence dosimetry, Environment, Archaeology.

\section{Introduction}

Radiation dosimetric investigations in diagnostic radiology have been increasing in importance in the last two decades. The most widely used method in radioactivity dosimetry is thermoluminescence technique [1]. Several types of thermoluminescent dosimeters (TLD) are commercially available for a wide range of applications: personnal, environmental and medical dosimetry, and archaeological dating, etc. Lithium fluoride doped with magnesium, copper, and phosphorus $\mathrm{LiF}: \mathrm{Mg}, \mathrm{Cu}, \mathrm{P}$ has recently emerged as TL material with significant advantages which outperformed many other materials [2]. Due to several important properties, such as tissue equivalence, relative low fading and low fading's high sensitivity, LiF has mainly been recommended for environmental measurements and radiotherapy. However, some disadvantages have also been described in previous work, mainly are

\footnotetext{
*Corresponding author. Tel.: 84-912865869.

Email: buithihong1504@gmail.com

https//doi.org/ 10.25073/2588-1124/vnumap.4222
} 
poor reproducibility and high residual signal [3, 4]. This paper aims to illustrate that, in the experimental conditions used in this study, $\mathrm{LiF}: \mathrm{Mg}, \mathrm{Cu}, \mathrm{P}$ (xeri GR-200) presents improved dosimetric characteristics that make it suitable for use in medical and environmental applications.

\section{Experimental}

Methodology. In this section we present the glow curve of the $\mathrm{LiF}: \mathrm{Mg}, \mathrm{Cu}, \mathrm{P}$ with the different proposed heating profiles.Preliminary experiments showed that the maximum temperature for LiF: $\mathrm{Mg}, \mathrm{Cu}, \mathrm{P}$ was a critical parameter and that the temperature of $240^{\circ} \mathrm{C}$ should be maintained stable during the first phase of the annealing cycle. It was also found that rapid cooling improved the phosphor response [5,6]. As regards the second phase of the annealing, although when using it a better reproducibility is found, the difference in performance is margina. The glow curves of thermoluminescence material were received from 4 dosimetersof $\mathrm{LiF}$ : $\mathrm{Mg}, \mathrm{Cu}, \mathrm{P}$ which were previously annealed. They were protected from light and irradiation with the following dose: $1 \mathrm{mGy}$, $2 \mathrm{mGy}, 3 \mathrm{mGy}$ and $5 \mathrm{mGy}$. To eliminate the low temperature peaks, the data acquisition of dosimeters' thermoluminescence intensitivity was performed 24 hours after the irradiation.

TL responsibility. Before package in capsults and exposure to radiation, $\mathrm{LiF}: \mathrm{Mg}, \mathrm{Cu}, \mathrm{P}$ powders received a standard annealing treatment. Depending on the type of thermoluminescene material, thermal annealing schemes were chosen to $\mathrm{LiF}: \mathrm{Mg}, \mathrm{Cu}, \mathrm{P}$ in this paper is: $240^{\circ} \mathrm{C}$ for 10 minutes. The method of slow cooling inside the muffle was used to reach room temperature for all cases (Figure 1). To study about TL responsibility material, 16 dosimetersof $\mathrm{LiF}: \mathrm{Mg}, \mathrm{Cu}, \mathrm{P}$ were prepared,and they were divided into groups of 4 . These dosimeterwere placed into capsules of latex, which are arranged adjacently to the gamma irradiation from Cobalt resource $\left({ }^{60} \mathrm{Co}\right)$. These were irradiated with the following doses: $1 \mathrm{mGy}, 2 \mathrm{mGy}, 3 \mathrm{mGy}$ and $5 \mathrm{mGy}$ (Figure 2).The dosimeters were also read at 24 hours postirradiation. In order to obtain the TL response as a function of the radiation dose, the TL intensities were plotted versus the obtained doses from gamma resource in the range of doses studied.The irradiation dosimeters were performed with a ${ }^{60} \mathrm{Co}$ resource.The readings of the TL materials are performed in a reader RGD-3A. The reading cycles were varied depending on the material as shown in Table 1. In order to eliminate the contribution by themoluminescence, all readings were performed in an atmosphere of high purity nitrogen $\operatorname{gas}\left(\mathrm{N}_{2}\right)$.

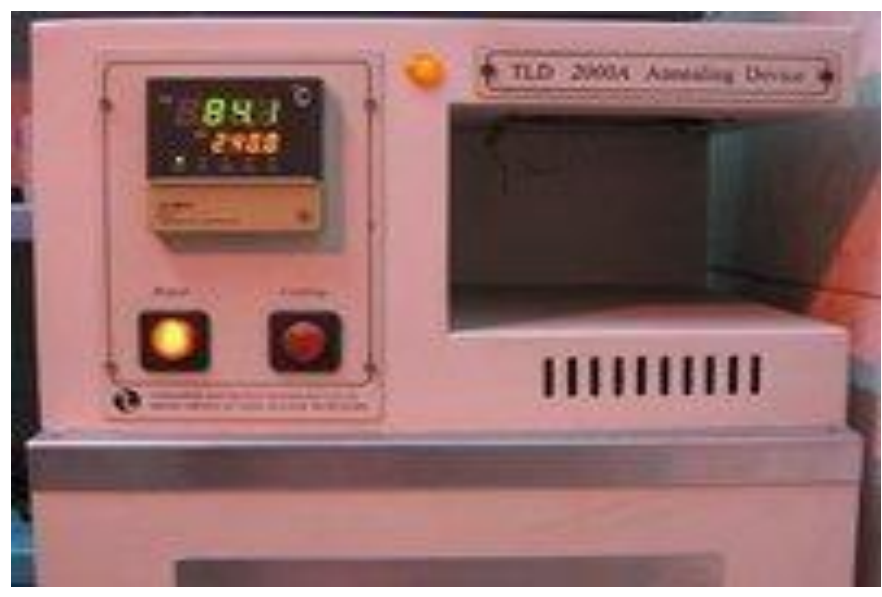

Fig 1. TLD 2000A Annealing Device. 


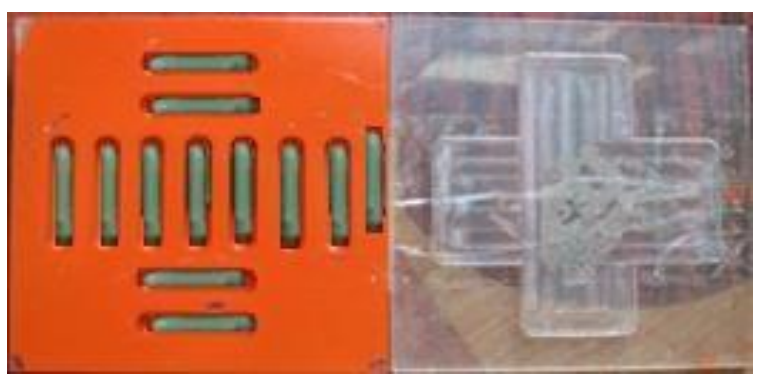

Fig 2. Capsules and rackscontainingTL material

Table 1. Reading parameters for TLD materials

\begin{tabular}{ll}
\hline Parameters & $\mathrm{LiF}: \mathrm{Mg}, \mathrm{Cu}, \mathrm{P}$ \\
\hline Preheating temperature & $135^{\circ} \mathrm{C}$ \\
Preheating time & $6 \mathrm{~s}$ \\
Preheating speed (It is chosen one of & $2 ; 4 ; 6 ; 8^{\circ} \mathrm{C} / \mathrm{s}$ \\
Max. Heating temperature & $240^{\circ} \mathrm{C}$ \\
Acquisition time & $6 \mathrm{~s}$ \\
Annealing temperature & $240^{\circ} \mathrm{C}$ \\
\hline
\end{tabular}

Fading of dosimeters. Fading of dosimeters as a function of time was studied. To do this, 12 dosimeterswere used, previously annealed, then they were irradiated at a dose of $5 \mathrm{mGy}$ and stored all the time at room temperature (around $25^{\circ} \mathrm{C}$ ). Readings were taken at the following postirradiation time: 3h, 24h, 48h, 72h, 96h, 144h, 192h, 240h, 288h, and 360h.

\section{Results and discussion}

Figures 3 presents thermoluminescence obtained glow curves for the LiF:Mg, $\mathrm{Cu}, \mathrm{P}$ materials at low doses of gamma resource (such as: $1 \mathrm{mGy}, 2 \mathrm{mGy}, 3 \mathrm{mGy}$ and $5 \mathrm{mGy}$ ), and read in heating rate $6^{\circ} \mathrm{C} / \mathrm{s}$.

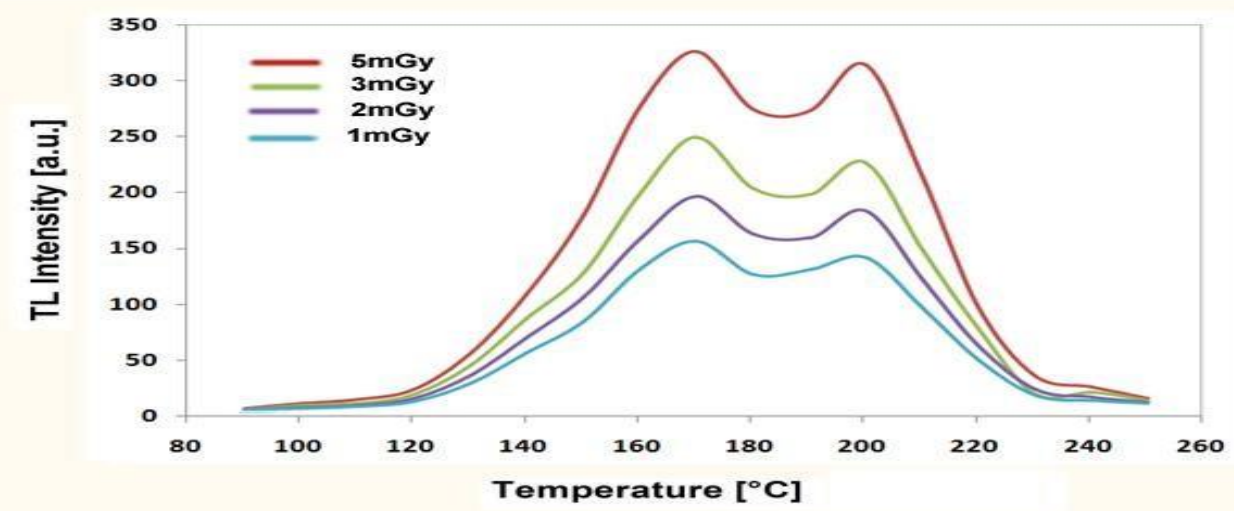

Fig. 3. The different glow curves of LiF: $\mathrm{Mg}, \mathrm{Cu}, \mathrm{P}$ 
In the Figure 3, dosimeter of $\mathrm{LiF}: \mathrm{Mg}, \mathrm{Cu}, \mathrm{P}$ has two peaks centered at $170^{\circ} \mathrm{C}$ and $215^{\circ} \mathrm{C}$. The dosimeters were readed at 24 hours post-irradiation. This results is also in correlation with Ginjaume's and Pradhan's investigation [2,3].In order to obtain the TL responsibility as function of the radiation dose for the materials, the TL intensities were plotted versus the obtained from gamma resource in the range of doses studied [6,7] .To investigate on TL sensitivity, there were 16 thermoluminescence dosimeter prepared. They were dived into 4 groups, corresponding to exposed doses: $1 \mathrm{mGy}, 2 \mathrm{mGy}$, $3 \mathrm{mGy}$ and $5 \mathrm{mGy}$. The TL insensitivities collect from the glow curves with the canals between $135^{\circ} \mathrm{C}$ and $210^{\circ} \mathrm{C}$ temperatures. The results were averaged of 5 reading times and showed in the Table 2.

Table 2. The TL insensitivities of the glow curves of LiF: $\mathrm{Mg}, \mathrm{Cu}, \mathrm{P}$

\begin{tabular}{lllll}
\hline $\begin{array}{l}\text { Heating } \\
\text { rate }\end{array}$ & \multicolumn{4}{c}{ Thermoluminescence intension (a.u) } \\
\hline$\left({ }^{\circ} \mathrm{C} / \mathrm{s}\right)$ & $\mathbf{1 m G y}$ & $\mathbf{2 m G y}$ & $\mathbf{3 m G y}$ & $\mathbf{5 m G y}$ \\
$\mathbf{2}$ & $560 \pm 20$ & $820 \pm 40$ & $1150 \pm 60$ & $1870 \pm 95$ \\
$\mathbf{4}$ & $650 \pm 30$ & $1150 \pm 50$ & $1650 \pm 85$ & $2350 \pm 110$ \\
$\mathbf{6}$ & $880 \pm 40$ & $1380 \pm 75$ & $2180 \pm 110$ & $3310 \pm 150$ \\
$\mathbf{8}$ & $780 \pm 35$ & $1310 \pm 60$ & $1810 \pm 90$ & $3050 \pm 140$ \\
\hline
\end{tabular}

As above present, the TL response of material was evaluated through TL intensity and irradiation dose. It is the angle of standard linear plotting versus the obtained doses and TL intensity (counts).

From Table 2, we have the plots to determinate TL response of $\mathrm{LiF}: \mathrm{Mg}, \mathrm{Cu}, \mathrm{P}$, as shown in the Figure4.

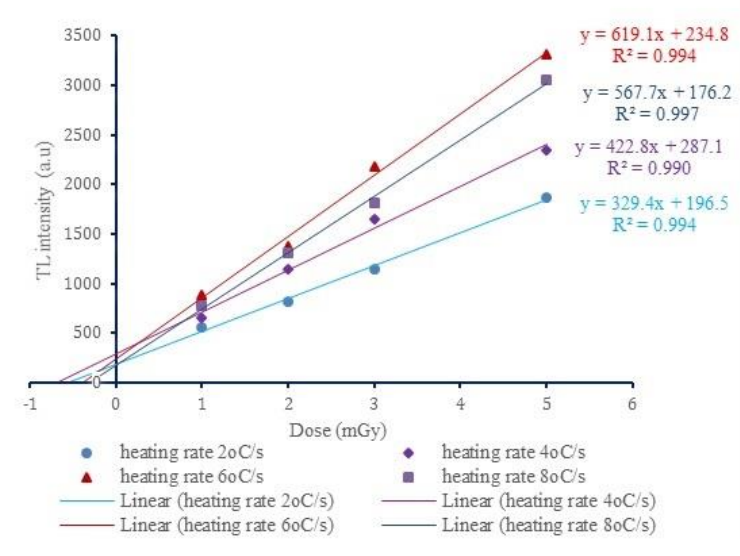

Fig 4. The TL response plots of $\mathrm{LiF}: \mathrm{Mg}, \mathrm{Cu}, \mathrm{P}$ with different heating rates.

Figure 4 have a good linearity of the TLintensity and the exposed doses in range studied values, with the relation factors $\left(\mathrm{R}^{2}\right)$ are over 0.9 values. Figure 4 also illustrated, TL responsibility changed depending on the heating speed, and it obtained maximum value around $6^{\circ} \mathrm{C} / \mathrm{s}$. This is shown in Figure 5. 


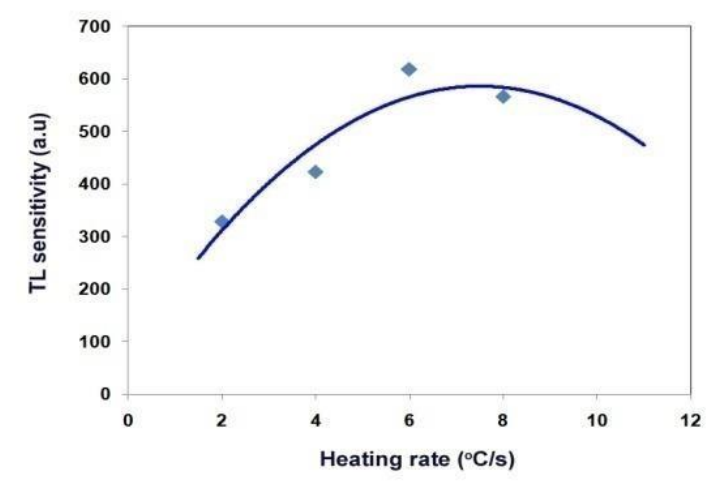

Fig 5.TL sensitivity versus heating rate.

Figure 5 shown that each thermoluminescence peak corresponds to energy level of electron trap in TL material $[6,8]$. When it was excited by temperature (heating), the electrons will be released from the traps and transmit to basic energylevel and radiates photons. Thus, released electrons from traps in TL material not only concern to co-referent energy level but also to heatingrate.

To study about the repeatability of the material at the environmental conditions, the total amount of 5 dosimeters were used. The test was performed for fifteen consecutive cycles, i.e., thermal annealing treatment, irradiation and reading with the same readout proceduresfor each annealing cycle. Annealing technique was conducted according to the conditions of $240^{\circ} \mathrm{C}$ for 10 minutes, the irradiation was performed at a dose of $5 \mathrm{mGy}$ and readings were made at 24 hours post irradiation using the same parameters mentioned above section. Results of investigation on reproducibility are shown in Figure 6.

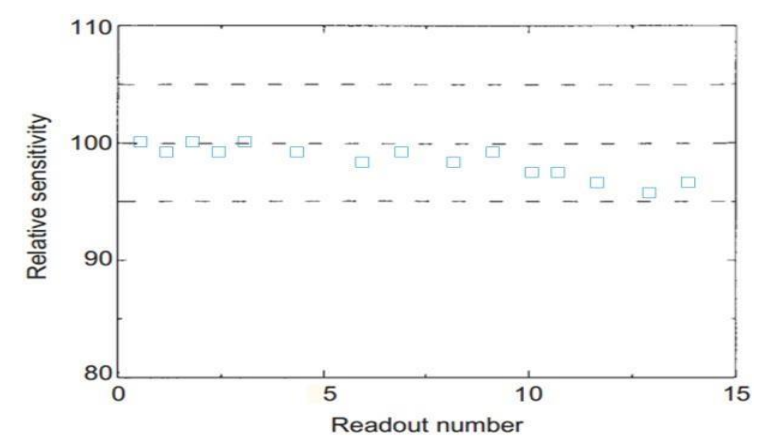

Figure 6. Reproducibility of $\mathrm{LiF}: \mathrm{Mg}, \mathrm{Cu}, \mathrm{P}$ through reused times.

Figure 6 illustrates the relative sensitivity variation from TL materials as a function of the number of reuses. Its reproducibility after 15 successive cycles of annealing, irradiation, and readout presented a little decrease. In addition, the residual signal obtained after an initial dose of $5 \mathrm{mGy}$ was lower than 5\% for the dosimeters with the proposed readout procedure.The decrease of TL response asafunction of time is shown in Figure 7.

In Figures 7 fading of peaks of glow curves for the $\mathrm{LiF}: \mathrm{Mg}, \mathrm{Cu}, \mathrm{P}$ materials are shown in a period of 15 days. It is observed clearly the slight decrease in the intensity of the dosimetric peak of the materials. Storing the TL dosimeter causes depopulation of trapping states due to 
fading. Therefore, the TL glow peaks shift to higher temperature with increase in storage time. $3 \mathrm{~h}$ and $48 \mathrm{~h}$ and slow fading $(8.8 \%)$ from $48 \mathrm{~h}$ until $360 \mathrm{~h}$ post irradiation. The results are similar to $[2,9]$.

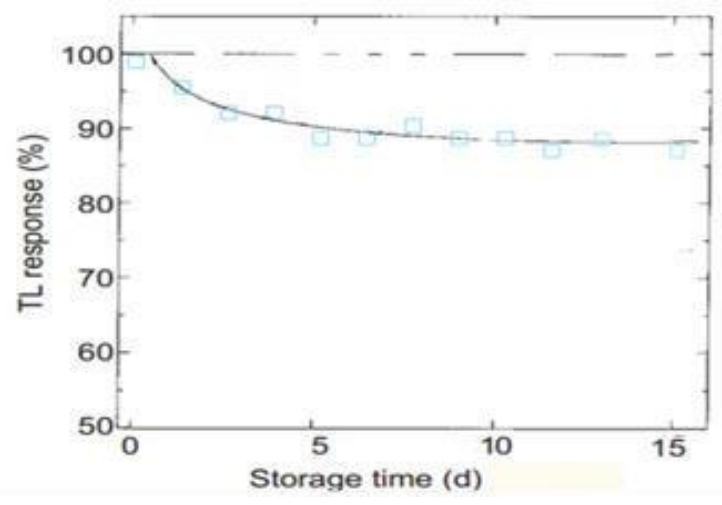

Figure 7. Fading of $\mathrm{LiF}: \mathrm{Mg}, \mathrm{Cu}, \mathrm{P}$ while storage room temperature $25^{\circ} \mathrm{C}$

\section{Conclusions}

This study demonstrates that, theCharacteristics of $\mathrm{LiF}: \mathrm{Mg}, \mathrm{Cu}, \mathrm{P}$ have been improved by working conditions in our laboratory. It is shown that because of its good energy response, low fading in natural environmental conditions and extended range of linearity. It is a suitable material for medical and archaeological applications.TL materials $\mathrm{LiF}: \mathrm{Mg}, \mathrm{Cu}, \mathrm{P}$ were characterized to low doses, which correspond to radiological diagnosis by the following dosimetric tests: homogeneity batch reproducibility, sensitive factor, detection threshold, linearity and fading. To observe glow curve of LiF: $\mathrm{Mg}, \mathrm{Cu}$, P, we suggest that, choosing a parameter "heating speed" around $6^{\circ} \mathrm{C} / \mathrm{s}$ is suitable for determination low doses. Reading TL insensitivity of $\mathrm{LiF}: \mathrm{Mg}, \mathrm{Cu}, \mathrm{P}$ need performed after $24 \mathrm{~h}$.

\section{References}

[1] L.A. Dewerd. L.K. Wagner. "Characteristics of radiation detectors for diagnostic radiology", Appl. Radiat. Isot. 50, (1999), 125-136.

[2] A.S. Pradhan. "Influenceof Heating Rate on the TL Responseof LiF TLD - 700, LiF:Mg,Cu,P and A12O3:C",Radiat Prot Dosim, 58, 3 (1995), 205-209.

[3] M. Ginjaume, X. Ortega, M. A. Duch, N. Jornet and A. SanchezReyes. "Characteristics of LiF:Mg, Cu,P for clinical application". Radiat Prot Dosi, 85, 1-4 (1999), 389-391.

[4] Vu Thi Thai Ha, Nguyen Thi Quy Hai, Nguyen Ngoc Long,Le Van Vu. "Preparation and characteristics of LiF:Mg,Cu,Na,Sithermoluminescent material". VNU Journal of Science, Mathematics - Physics 23 (2007) 225231.

[5] M.Oberhofer., A.Scharmann. "Applied Thermoluminescence Dosimetry”. AdamHilger, Bristolm(1981).

[6] S.W.S. McKeever. "Thermoluminiscence of Solids”, World Scientific, First edition, New Jersey(1985).

[7] C.R. Watson. "Linearity of TLD response curves". Health Phys, 18, (1970) 168-169.

[8] D.R. Vij, "Thermoluminescent Material”, Prentice-Hall, Englewood Cliffs NJ, 1993.

[9] C.R. Hirning. "Detection and determination limitsfor thermoluminiscence osimetry".Health Phys. 62(3), (1992) 223-230. 